\title{
Embrittlement of Mild Steels during Hot Dip Galvanization
}

\author{
Michael Panzenböck ${ }^{1}$, Patric Schütz ${ }^{1}$ \\ ${ }^{1}$ Department of Physical Metallurgy and Materials Testing, Montanuniversität Leoben, Austria
}

In many cases a predominant failure mechanism of parts and components made of structural steels is fatigue. Such damage is followed by a ductile or brittle residual fracture. Unfortunately, we may sometimes observe a disastrous brittle damage of steels, which show plastic deformation and ductile fracture under normal loading conditions. Many reasons are responsible for such material behaviour. On the one hand, low surrounding temperatures, local stress concentrations (e.g. notches, cracks) and impact loading, favour brittle fracture. On the other hand, brittle material response or a shift of the transition temperature to higher values is a consequence of inadequate microstructure (Widmannstätten structure), blue brittleness and temper embrittlement (due to carbon, phosphorous and impurities on grain boundaries) as well as high nitrogen contents in steels with low aluminium concentration. Hydrogen or hydrogen induced stress corrosion cracking and liquid metal embrittlement lead also to disastrous failure. Zinc layers may cause brittle fracture, too.

Fig. 1a gives an overview of parts of broken hangers, used to fix belt conveyors on the ceiling of a mine. They were manufactured by bending a wire (12 $\mathrm{mm}$ in diameter) made of mild steel of the type S235JR (AISI 570-36). To protect them against corrosion, all parts were plated with a thin zinc layer. For this hot dip galvanisation was used. The broken parts reveal plastic deformation. A more detailed investigation of the fracture surface (Fig. 1b) shows a glittering structure and a dark spot at the edge of all broken parts. The latter can be attributed to the point of crack initiation. Therefore, the cracks start from the inner side of the bended wire. This phenomenon is clearly visible in Fig. 2a, where the bending zone is depicted. After metallographic preparation the parts reveal many branched cracks starting from the edge of the hanger (Fig. $2 b)$. All these cracks are coated with a more or less thick layer of zinc. From fractographic investigations it is visible (Fig. 3a, b) that the initial crack can be attributed to liquid metal embrittlement. A typical feature within these zones is the separation of grain boundaries. This damage is followed by cleavage fracture (Fig. $3 b)$, caused by the initial sharp cracks and impact loading at low ambient temperature.

From Fig. 2a we can point out that cracks are initiated within very small zones on the inside of the bending radius. The location of the main cracks is not exactly within the compression region during bending. Plastic bending deformations during manufacturing cause residual tensile stresses within the original compression zone, whereas the stresses within original tension zone change from tension to residual compression stresses. The localisation of the highest tensile stresses depends on the manufacturing procedure and on the used tools. Detailed information is provided by finite element calculation. Varying the geometry of the tools does not lead to the highest tensile stresses being located at the inner bending radius.

However, in this case of damage also unbroken elements were found. These parts were produced in the same way. No cracks could be detected. Such hangers revealed only plastic deformation. The difference in cracking can be explained by the chemical composition of the steels used for the hangers. The main alloying elements like carbon, manganese, silicon and other elements in broken and unbroken are comparable. This statement is not true for tin. The broken parts reveal more than $0.1 \mathrm{wt} \%$ tin compared to the unbroken hangers. 


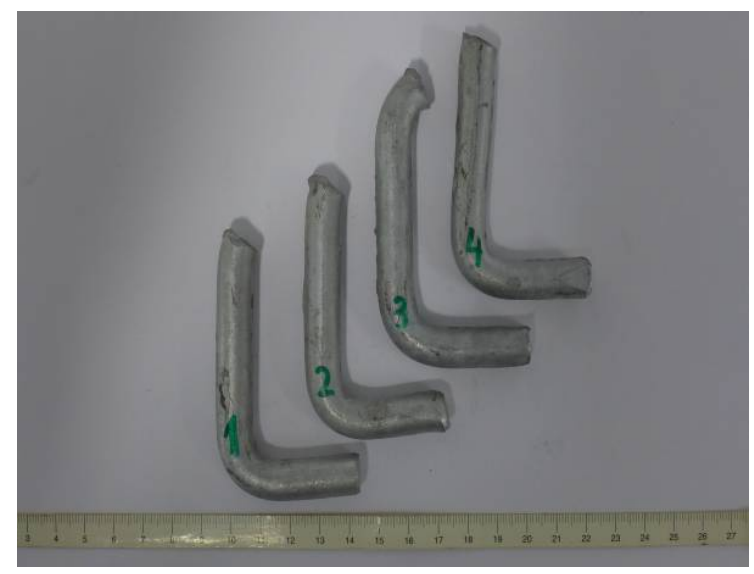

Figure 1a. Macroscopic overview of four parts of broken hangers. Arrows mark the fracture surface.

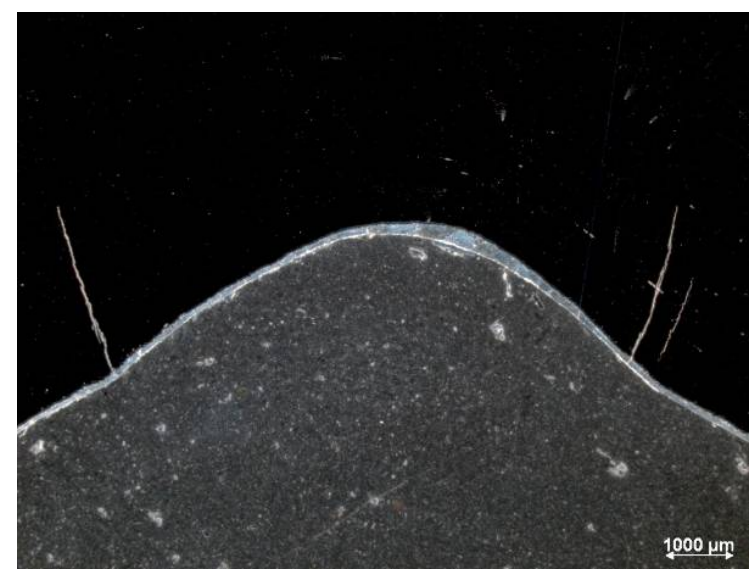

Figure 2a. Metallographic cross section through the bended wire (dark field). Cracks are clearly visible as white lines.

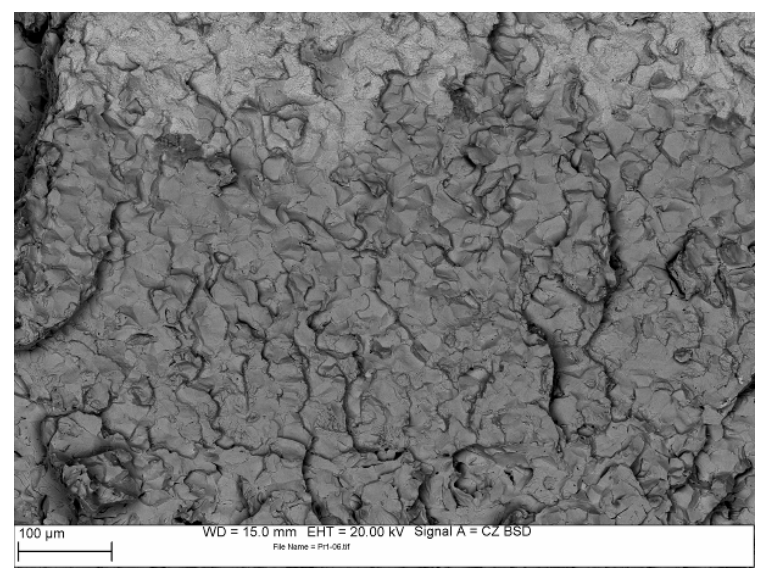

Figure 3a. Fractographic investigation of the fracture surface (dark spot). The inter-granular fracture zone is covered with zinc.

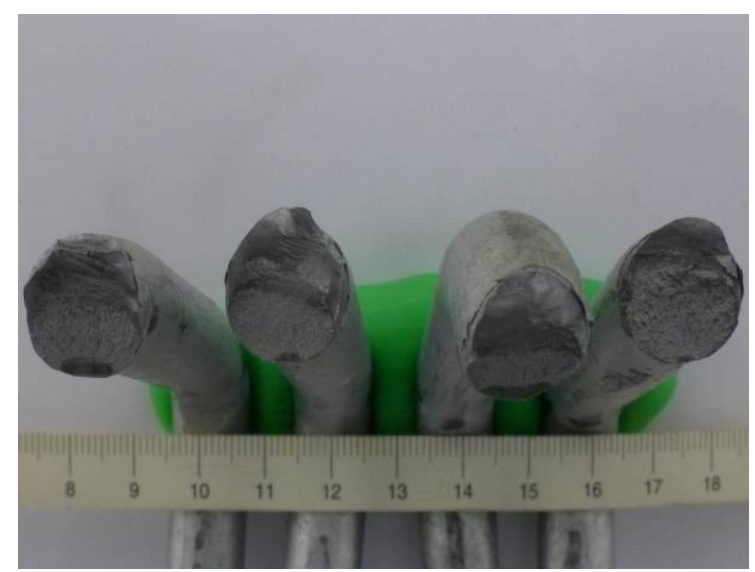

Figure 1b. Macroscopic overview of the fracture surface. Arrows mark regions of crack initiation (dark spots).

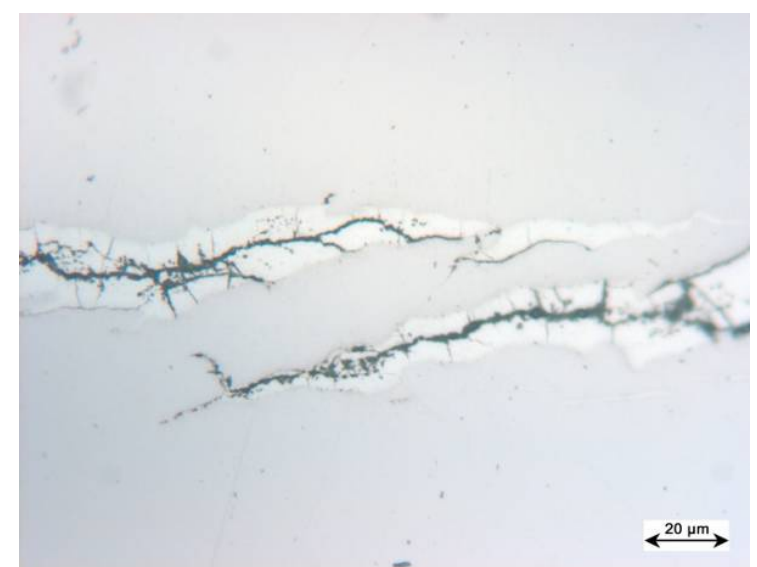

Figure 2b. Detail from Fig. 2a (crack 1). Main crack and crack branches are covered with zinc.

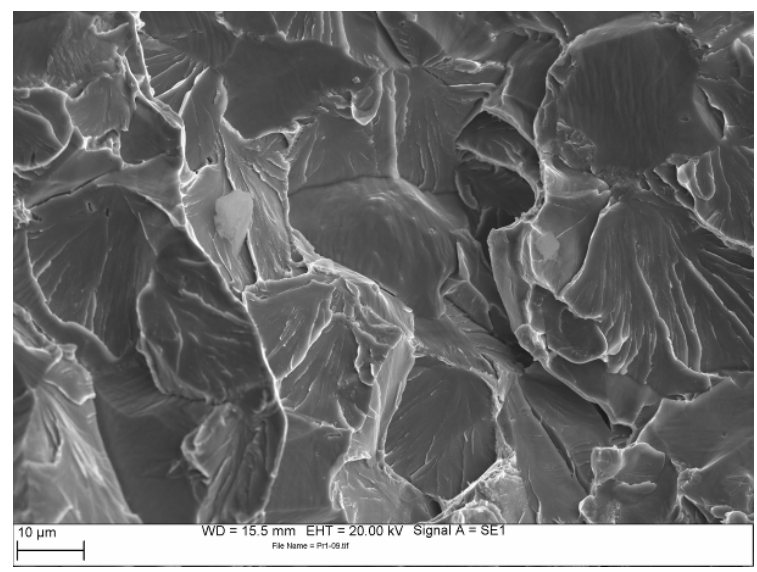

Figure 3b. Fractographic investigation of the fracture surface behind the dark spot. Cleavage fracture is prevalent. 